\title{
Possibilities for small hydro power plant construction in the old bed of the river Drava
}

\author{
K. Deželak ${ }^{1}$, J. Pihler $^{1}$ and G. Štumberger ${ }^{1}$ \\ ${ }^{1}$ Power Laboratory Department \\ Faculty of Electrical Engineering and Computer Science, University of Maribor \\ Smetanova 17, 2000 Maribor, Slovenia \\ Phone/Fax number:+386 22207180 / +386 2220 7272, e-mail: klemen.dezelak@uni-mb.si
}

\begin{abstract}
This paper presents alternative possibilities for construction of small hydro power plants in the old bed of river Drava (Slovenian part near Maribor city). The nature in this area is protected by special environmental laws. The technical solutions regarding exploitation of the energetic potential in the old bed of river Drava and the results of economical justification analysis of investment are indicated. In that sense the river is analysed and suitable locations for hydro power plant construction are defined.
\end{abstract}

\section{Key words}

Hydro power plant, financial part, matrix turbine, movable hydro power plant.

\section{Introduction}

Hydro energy is one of the most reliable and the cost effective renewable sources of energy [1]. From statistics [1] - [3], it is obvious that hydropower occupies the first place in the world among all of the renewable energies. One of the most popular structures for the hydro energy exploitation is so called small hydro power plants.

Small hydro power plants can be observed from two points of view, architectural and electro-mechanical [4], [5]. The main architectural emphasis is on the construction of the dam, the power house and the water intake [5], [6]. The dam and the water intake direct the water towards the channel, tunnel, penstock or the guide blades. The water flows through the runner blades at the turbine, which rotates with a sufficient speed in order to create the electrical power in the generator. Finally, the water leaves the plant through the draft tube. Small hydro power plants require less maintenance, during the lifetime, which could be even more than 50 years [7], [8].

There is no need for long transmission lines because output is consumed near the source. The technology is easy to adopt, whilst the high performing electrical equipment can be easily found on the market [1]. Under specific circumstances, small hydro power plants represent one of the cheapest methods of electrical energy generation. A small hydro power plant is characterized by flexibility and reliability of operation, which includes fast start-ups and shutdowns [1].

This work deals with special solutions for small hydro power plan constructing inside the old bed of river Drava (Fig. 1).

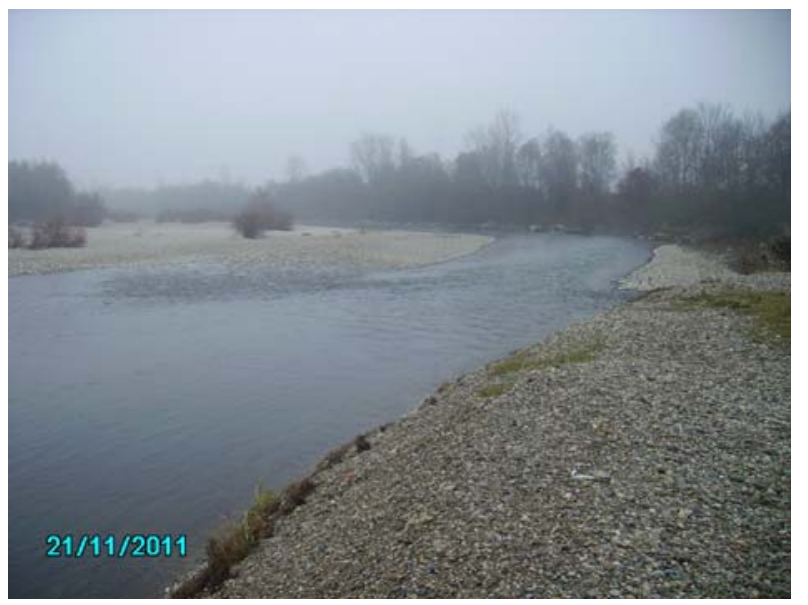

Fig. 1. Old bed of river Drava.

The river Drava is near hydro power plant "Mariborski otok" divided in two sections, one section is channel leading to the next hydro power plant "Zlatoličje", while the other part of the water flows through the old river bed (Fig. 1). The length of aforementioned old river bed is approximately $25 \mathrm{~km}$.

Heavy rainfall in central parts of Europe can often cause the increased flow of the river. Therefore, the hydro power plant Mariborski otok needs to pour the water over the dams. The channel of the river Drava can accept only a restricted amount of water, so the remaining flow is released down the old bed of the river Drava (in case of high levels of water the flow in the channel of the river Drava amounts only to $271 \mathrm{~m}^{3} / \mathrm{s}$ and during normal operation to $450 \mathrm{~m}^{3} / \mathrm{s}$ due to the protection of hydro power plant Mariborski otok against a backward wave). 
It has occurred many times that some settlements near the old river bed were flooded, especially around the area of Duplek.

During normal operation the mean flow in the old bed of the river Drava is equal to $10 \mathrm{~m}^{3} / \mathrm{s}$ or $20 \mathrm{~m}^{3} / \mathrm{s}$ depending on seasonal time:

- $Q_{\min 1}=10 \mathrm{~m}^{3} / \mathrm{s}$ during period from 15.10 to 15.03 ,

- $Q_{\min 2}=20 \mathrm{~m}^{3} / \mathrm{s}$ during period from 16.03 to 14.10 .

Different technical solutions for exploitation of the energetic potential in the old bed of river Drava and the results of economical justification analysis of investment are dealt with in this paper. In that sense it should be considered that the area of the old bed of the river Drava is a protected area and belongs into the network of the protected areas Natura 2000. The forming of the network of specially protected areas Natura 2000 is regulated by the Nature Conservation Act. So, all of the discussed solutions must consider the aforementioned fact.

\section{Technical solutions}

Figs. 2 and 3 show the flow in the old bed of the river Drava in year 2007. Is it obvious that most of the time in the river is only 10 or $20 \mathrm{~m}^{3} / \mathrm{s}$ of water, while especially during the autumn some periods with high water appear. The maximal flow in year 2007 was equal to $1558 \mathrm{~m}^{3} / \mathrm{s}$. Complete old river bed $(25 \mathrm{~km})$ was divided into 76 cross profiles where the average distance between profiles is 329 m. Figs. 4 and 5 shows profiles, with normal levels of water, denoted as No. 48 and No 49. It seems that location between profiles No. 48 and No. 49 is appropriate for small hydro power plant. Conditions between this two profiles are also shown in Fig.1. This location was primary chosen because in this area the bridge across the river will be (probably) constructed as well.

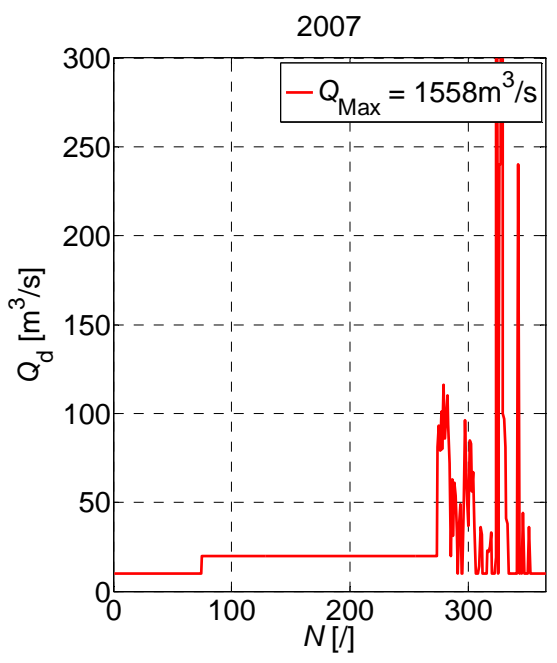

Fig. 2. Flow in old bad of river Drava.

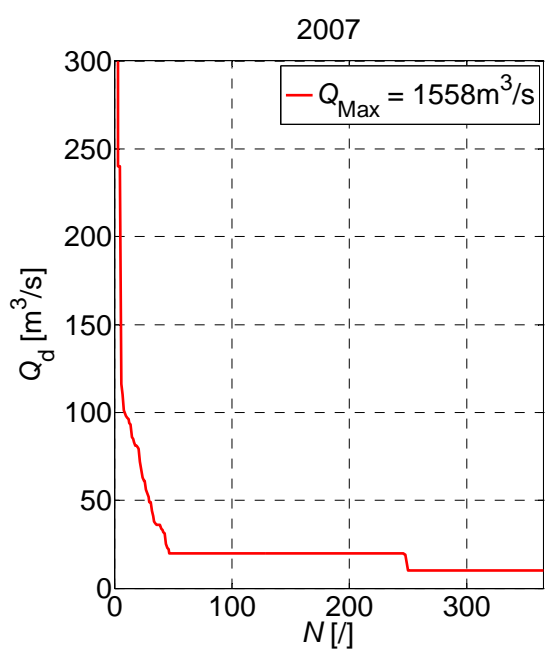

Fig. 3. Flow in old bad of river Drava - from maximal to minimal value.

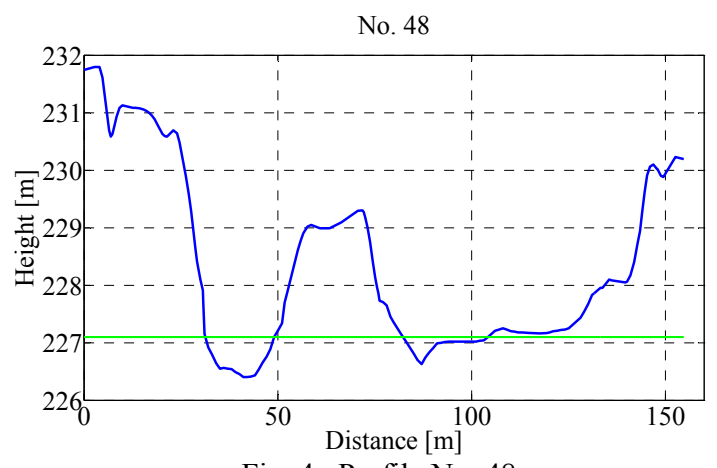

Fig. 4. Profile No. 48.

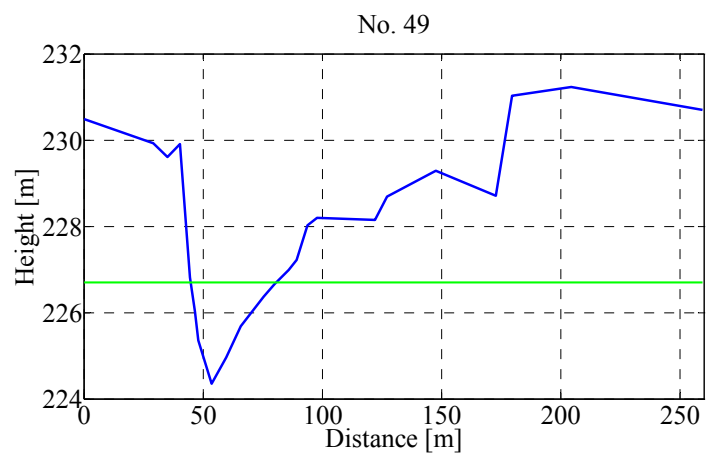

Fig. 5. Profile No. 49.

The complete situation without and with bridge and small hydro power plant (SHPP) is shown in Figs. 6 - 8.

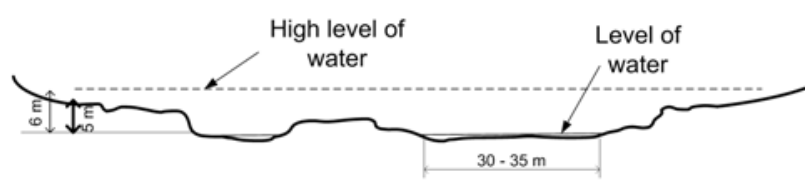

Fig. 6. Profile of appropriate location for SHPP construction without bridge. 


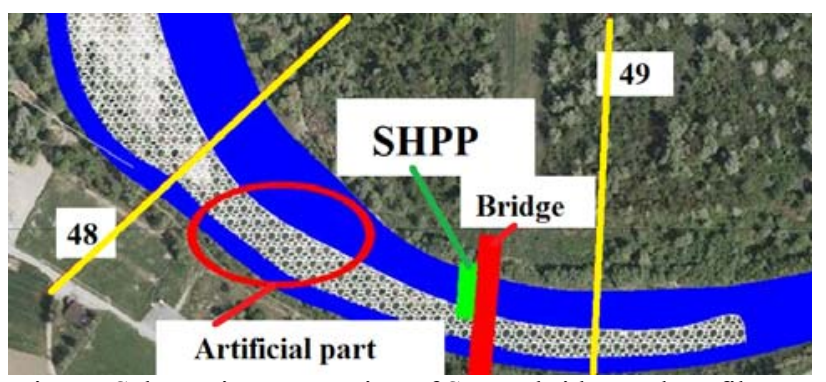

Fig. 7. Schematic presentation of SHPP, bridge and profiles No. 48 and No. 49.

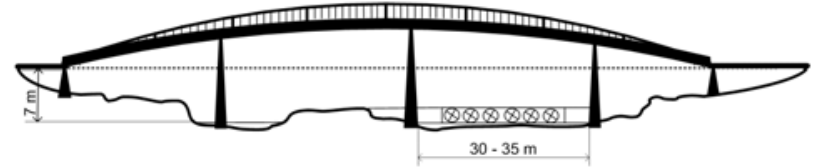

Fig. 8. Profile of appropriate location for SHPP construction with bridge.

First proposed solution for small hydro power plant construction is based on construction of so called movable hydropower plant, where power house can be lifted in order to allow for direct sediment transport [9]. Another chosen solution is based on hydromatrix techonology. Hydromatrix is an innovative concept of hydraulic energy generation that combines the advantages of proven technology and low cost installation, and can be even easily integrated into existing dam structures [10].

\section{A. The movable hydro electric power plant}

The innovative movable hydro power plant of overflow and underflow type was for the first time integrated into the existing weirs without additional water diversion [12]. So, rather the diverted water in the canals is reduced and more water remains in the river, leading to an ecological improvement [11], [12]. Some advantages and characteristics of the moveable hydropower plant are listed below [11], while detailed view of generation module and structure of whole system are shown in Figs. 9 and 10.

- Innovative hydropower plant for low head differences.

- Unobtrusive.

- Low noise level.

- Higher energy output by usage of ejector effects.

- Low maintenance.

- Fewer operating costs.

- Lower construction costs.

- More economic operation.

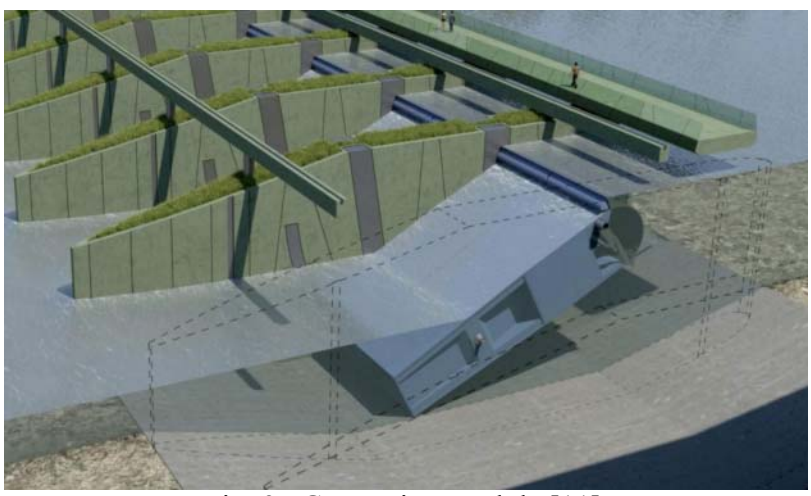

Fig. 9. Generation module [11].

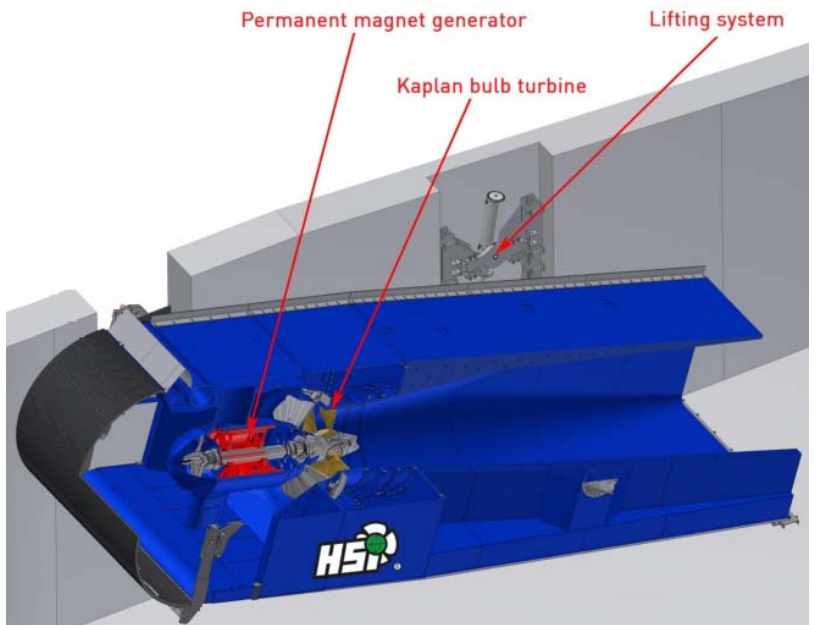

Fig. 10. System structure [11].

\section{B. Hydromatrix technology}

The hydromatrix technology [13] is one of the most economically viable solutions for the generation of renewable energy from hydropower [14]. It utilises existing dam structures where more or several dam gates are replaced by so-called modules consisting of several dozens of small scale generators [14]. Therefore, the major source of cost in the construction of a hydro power plant, namely civil works, is reduced to a moderate amount. Fig. 11 shows a hydromatrix module, while Fig. 12 shows the close-up of a single asynchronous generator as one of the major constituents of the module [14].

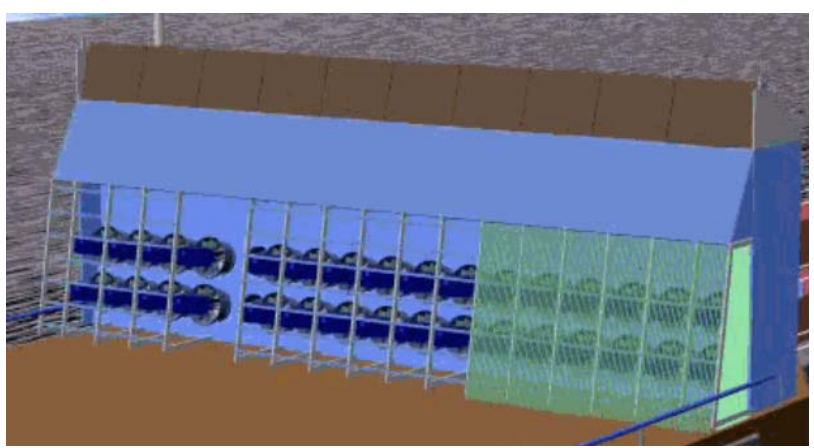

Fig. 11. System structure [14]. 


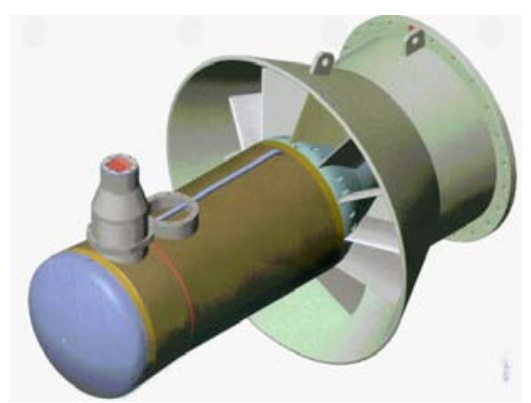

Fig. 12. Single asynchronous generator [14].

\section{Financial part}

The power and produced energy of the hydro power plant are mainly dependent on the available river flow - Fig. 2. To calculate the delivered energy, instead of curve in Fig. 2 , the curve shown in Fig. 3 should be considered within calculations [2] - [4]. Apart from flow duration curve, the values of gross head, type of used turbine, design flow and generator efficiency are very important. In our case gross head is equal to $2 \mathrm{~m}$, while design flow is equal to $20 \mathrm{~m}^{3} / \mathrm{s}$. In the basis of above input parameters the power of our hydro plant is equal to $336 \mathrm{~kW}$ (hydromatrix) and $391 \mathrm{~kW}$ (movable), while produced energy in one year is equal to $2461 \mathrm{MWh}$ (hydromatrix) and $2713 \mathrm{MWh}$ (movable).

Within financial part the curve of cumulative cash flow could be calculated by yearly income and outcome difference, where parameters like inflation, credit and varying cost of energy could have essential influence. Belonging to the cumulative cash flow curve the year-topositive cash flow parameter has very important meaning. It shows the number of years where the value of cumulative cash flow is equal to zero [4]. All calculations are obtained for the initial costs $7000 \mathrm{EUR} /$ year (hydromatrix) and 5500 EUR/year (movable), project life 30 year, credit $50 \%$ of initial costs and credit term 10 years. Fig. 13 shows the cumulative cash flow curves for both aforementioned solutions. The locations, where curves cross the value zero (10 - 12 years) represent year to positive cash flows.

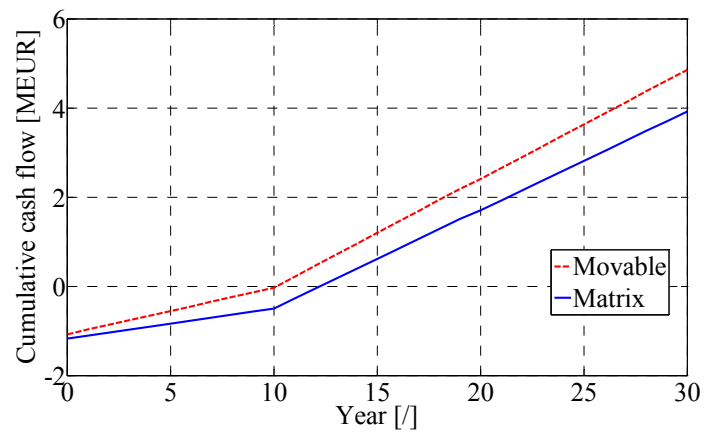

Fig. 13. Cumulative cash flow curves.

\section{Conclusion}

This article deals with comparison between the two options (movable hydro power plant and hydromatrix power plant) of building small hydro power plants on the river bed with a relatively small flow. Within the technical part of calculations the power and produced energy were evaluated, while within the financial part we determined the curve of cumulative cash flow. Based on the comparison, it is evident that movable hydro power plant could represent better option. It is still necessary to say that the use of matrix turbines for application in small hydro power plants is often discouraged, mostly due to bad financial indicators within investment evaluation.

\section{References}

[1] C. Dragu, T. Sels and R. Belmans, "Small hydropower state of the art and applications", Int. Conf. on Power Generation and Sustainable Development, AIM, 2001, Liege, Belgium

[2] O. Paish, "Small hydro power: technology and current status", Renewable and Sustainable Energy Reviews, 2002, 6, pp. $537-556$.

[3] K. Deželak,, "Cost of Energy Produced by a Small Hydro Power Plant Defining", 2011, Conference OWD, Poland.

[4] K. Deželak, K. Dežan, J. Pihler and G. Štumberger, "Investment evaluation for a small hydro power plant", Journal of energy technolohy, 2008, Vol. 1.

[5] N. G. Voros, C. T. Kiranoudis and Z. B. Maroulis, "Shortcut design of small hydroelectric plants", Renewable Energy, 2000, pp. 545-563.

[6] S. C. Li, "A high-performance and low-cost propeller turbine for small hydro schemes", American Society of Mechanical Engineers 2001 Fluids Engineering Division Summer Meering, New Orleans, Louisiana.

[7] A. D. Karlis and D. P. Papadopoulos, "A systematic assessment of the technical feasibility and economic viability of small hydroelectric system installations", 2000, Renewable Energy, 20 (2), pp. 253-262.

[8] S. M. H. Hosseini, F. Forouzbakhsh and M. Rahimpoor, "Determination of the optimal installation capacity of small hydro-power plants through the use of technical, economic and reliability indices", 2005, Energy Policy, pp. 1948-1956.

[9] ICPDR "Hydropower case studies and good practice examples", International Commision for the Protection of the Danube River, 2013.

[10] Http: http://www.andritz.com/hydro/hy-others-andritzhydro/hy-hydromatrix.htm

[11] EU - LIFE Projekt ENV/D/000485, The movable hydro electric power plant, Hydro-energie ROTH GMBH

[12] WP6.1 MIF definition and use for hydropower production (Report), Sustainable Hydropower in Alpine Rivers Ecosystems, Version 2.0, 2012

[13] B. Quinlan and A. C. Bihlmayer, "Smithland and Cannelton hydromatrix projects - a new concept in hydroelectric power generation on the Ohio river", Proc. Hydrovision, 2002

[14] E. Schlemmer and F. Muller, "Electromagnetic Finite Element Calculations of Permanent Magnet Generators for ECOBulb and Hydromatrix Applications", Proceedings of the International conference on renewable energies and power quality (ICREPQ' 03), 2003, Spain. 